\title{
Thermoelastic properties nanocomposite chloroprene of rubber with montmorillonit
}

\author{
S.M. Ponomarenko \\ Institute of physics of NAS of Ukraine, av. Nauki 46, Kyiv, 03028, Ukraine \\ Tel.: +380445251220 \\ E-mail:ponomarenko_sm@gmail.com \\ Article info: received 02.11.2020, revised 27.11.2020, accepted 17.12.2020
}

Ponomarenko, S.M. (2020) Thermoelastic properties nanocomposite chloroprene of rubber with montmorillonit 4(49), DOI: $10.26909 /$ csl.4.2020.3

The problem that arises during the operation of tires is cyclic deformation, in which there is a conversion of mechanical energy into heat. However, due to the low thermal conductivity of rubber, repeated cyclic loads of products based on them lead to heating, which is due to the phenomenon of mechanical hysteresis. The consequence is a deterioration of their performance over time and, as a consequence, a reduction in service life.

The main method for increasing the interfacial interaction for ceramic fillers is to ensure the penetration of rubber molecules into the interplanar space (gallery) formed by the filler particles (intercalation), and the subsequent distribution of these nanoplates (exfoliation) to a thickness of several nanometers throughout the field.

The aim of this work is to study the thermoelastic properties of rubbers made on the basis of nanosized mineral filler montmorillonite, which may indicate a way to solve the problem of their durability.

It was investigate the influence of modified nanosize montmorillonit on thermoelastic properties of rubber composites on it basis. It is routined that thermoelastic properties described a model, which takes into account holdings of local increase of tension for a rubber matrix and destruction of spatial net of nanoparticles with the increase of strain, which results in exotherms which show up as a result of friction between the filler particles.

Quantitative analysis of the thermoelastic properties of rubber nanocomposites provides additional confirmation of the concept of the reinforcement factor, which depends on the deformation, and determines the thermoelastic properties of nanocomposites for the whole range of relative elongations.

Key words: nanosize montmorillonit, thermoelastic properties, rubber composites.

\section{Термопружні властивості нанокомпозитів хлоропренового каучуку $з$ монтморилонітом}

\section{С.М. Пономаренко}

Інститут фізики НАН України, Київ, Україна

Досліджено вплив модифікованого нанорозмірного монтморилоніту на термопружні властивості каучукових композитів на його основі. Показано, що термопружні властивості описуються моделлю, що враховує внески локального збільшення напружень для каучукової матриці та руйнування просторової сітки наночастинок із збільшенням напружень, що призводить до екзотермічних ефектів, які проявляються в результаті тертя між частинками наповнювача.

\section{Вступ}

Змішування каучуків в розплаві 3 мінеральними наповнювачами та подальша їх вулканізація використовувались протягом багатьох десятиріч для покращення експлуатаційних властивостей гум, виготовлених на їх основі. Однак всі наповнювачі виявляють здатність до утворення своїх власних структур (великі вторинні агрегати частинок наповнювача 3 внутрішніми порожнинами, недоступними 
для взаємодії з матрицею каучуку). Внаслідок цього взаємодія на межі розділу фаз каучук/наповнювач сильно зменшується [1], що призводить до знижених характеристик гум в порівнянні 3 теоретично очікуваними. Основний метод по збільшенню міжфазної взаємодії для керамічних наповнювачів полягає у забезпеченні проникнення молекул каучуку в міжплощинний простір (галереї), утворений частинками наповнювача (інтеркаляція), та подальше розподілення цих нанопластин (ексфоліація) до товщини порядку декількох нанометрів по всій матриці каучуку [2], що передбачає модифікацію їх поверхні. Гуми, приготовлені за цією технологією, виявляють покращені властивості при відносно низькому вмісті наповнювача [3]. Наприклад, збільшення модуля Юнга та межі міцності на розрив при введенні в натуральний каучук 10 мас. \% монтморилоніта, обробленого органічним катіоном, рівноцінне введенню 40 мас. \% технічного вуглецю, що помітно перевищує ці показники для кремнезему при тих же ступенях наповнення [3].

Іншою проблемою, що виникає при експлуатації гум, є циклічні деформації, при яких відбувається перетворення механічної енергії в теплову. Однак, із-за низької теплопровідності гум багаторазові циклічні навантаження виробів на їх основі призводить до розігріву, що обумовлений явищем механічного гістерезису. Наслідком цього є погіршення їх експлуатаційних властивостей з часом i, як наслідок зменшення строку експлуатації.

Мета роботи. Метою даної роботи є дослідження термопружних властивостей гум, виготовлених на основі нанорозмірного мінерального наповнювача монтморилоніта, які можуть вказати шлях до вирішення проблеми їх довговічності.

\section{Матеріали та методи дослідження}

В якості вихідної каучукової матриці для дослідження був вибраний синтетичний хлоропреновий каучук меркаптанового класу (Baypren 110, Bayer AG). Наночастинки комерційної органоглини $\mathrm{OC}_{2}$ (Nanofil, Süd-Chemie) були попередньо оброблені діоктадецл-диметил амонієвою сіллю. Постачальником вулканізаційних агентів та стабілізаторів (стеаринова кислота, окис цинку $\mathrm{ZnO}$, окис магнію $\mathrm{MgO}$ та Ренорган ETU-80) є Bayer AG.

Композити були приготовлені в два етапи. На першому етапі, каучук був змішаний в розплаві $3 \mathrm{OC}_{2}$ при $353 \mathrm{~K}$, в якому був використаний внутрішній змішувач (Haake Rheocord 90); через 7 хв. були добавлені вулканізаційні реагенти і змішування відбувалось ще 3 хв.; згодом композити були гомогенізовані з допомогою вальцювання. (Exakt 80S) при 333-353 К. На другому етапі зразки вулканізувались сіркою в вакуумному пресі (Collin) під тиском 30 бар при 433 К протягом 50 хв., що детально описано в роботі [4]. Маркування зразків приведені в табл. 1.

Результати ширококутового рентгенівського розсіювання (ШКРР) в діапазоні кутів $2 q$ від 5 до $40^{\circ}$ були отримані на дифрактометрі ДРОН-4,0. Дифрактограми були нормовані на товщину та коефіцієнт поглинання.

Дослідження методом малокутового рентгенівського розсіювання (МКРР) в області кутів від 3 до $5^{\circ}$ були проведені дифрактометром, що використовує метод колімації Краткі (PAAR, Gras, Австрія) 3 поступовим скануванням сцинтиляційного лічильника, який аналогічний дифрактометру типу КРМ.

Питома теплоємність $c_{p}$ вимірювалась (температурний інтервал 215 - 380 К, швидкість нагрівання $100 \mathrm{~K} /$ хв.) установкою ДСК (Perkin Elmer DSC-2 удосконаленим).

Механічна робота $W$ та супутні теплові ефекти $Q$ в циклах поступового навантаження розтягування/ скорочення вимірювались (з оціночною похибкою нижче 2 \%) при кімнатній температурі деформаційним калориметром, що детально описаний в роботах [5]. В області низьких кратностей деформації $(\lambda<1,10-1,20)$ кожен зразок розтягувався 3 постійною швидкістю $q^{+}$(10 \% від загальної довжини зразка за хвилину) до певної $\lambda_{i}$, витримувався при цій $\lambda_{i}$ до повного завершення механічної та теплової релаксацій, потім скорочувався при тій же швидкості $q$ до нульової сили. Величина різниці між фіксованими крайностями деформації в двох послідовних кроках $\Delta \lambda=\lambda_{i+1}-\lambda_{i}$ коливалась в межах $10^{-4}-10^{-3}$. При великих видовженнях механічна робота та теплові ефекти вимірювались тільки в режимах ступінчатого розтягування при більших значеннях $\Delta \lambda$ (близько $10^{-2}$ ).

\section{Результати та їх обговорення}

Основні особливості кривих ШКРР для вихідного каучуку (рис. 1а) - це дифузні аморфні галло 3 максимумом, близьким до вектора розсіювання $q_{0} \approx 13,2 \mathrm{Hм}^{-1}$ (який відноситься до міжланцюгової відстані $\left.d_{0}=2 \pi / q_{0} \approx 0,48 \mathrm{Hм}\right)$, та кілька гострих рефлексів при більших значеннях вектора розсіювання. Профілі ШКРР для композитів в основному подібні; однак, три додаткові рефлекси біля $q \approx 15,3$; 14,2 та 3,4 нм-1 проявляють тенденцію до збільшення інтенсивності із збільшенням вмісту наповнювача $w$ (рис. 1a).

Останній рефлекс (відповідає періодичності 1,9 нм) і відноситься до міжплощинної відстані необробленого монтморилоніту. Два попередні рефлекси, можливо, відносяться до областей квазікристалічної упаковки сегментів каучуку в безпосе- 


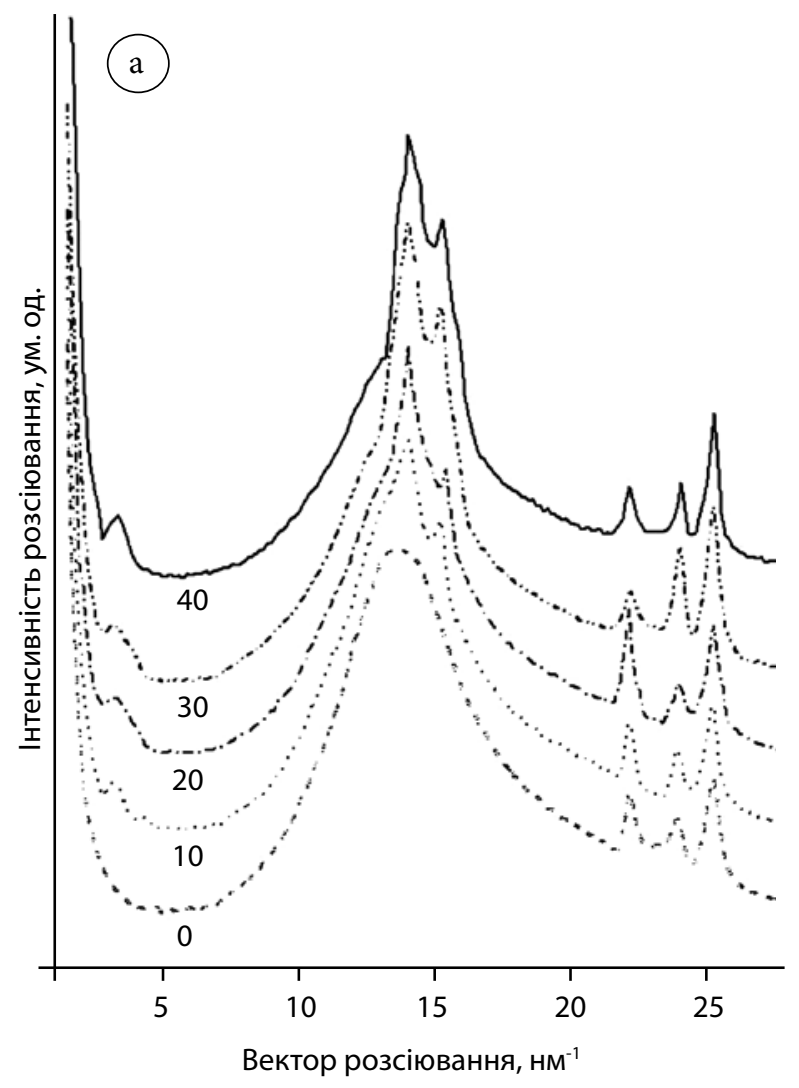

Рис. 1. Криві ШКРР (а) та МКР (б) для досліджуваних зразків. редній близькості до поверхні частинок (зазвичай називають як «граничний шар» (ГШ) [6]).

Товщина ГШ $\Delta r$ може бути оцінена 3 наступного співвідношення [16]

$$
v_{B I}(1-w) v_{B I}=\Delta r s w
$$

де $v_{B I}$ та $v_{B I}-$ відповідно об'ємна доля та питомий об'єм ГШ; $s-$ питома поверхня наповнювача. Таким чином, приблизно лінійне зростання „кристалічності” хлоропренового каучуку $X_{ш к P P,}$ яке може бути визначене як $v_{B I} 3$ відношенням $w /(1-w)$ (рис. 2), говорить про постійне значення $\Delta r$ для досліджуваних нанокомпозитів. Величина $\Delta r \approx 0,33$ нм, отримана $з$ нахилу кривої, $S=\Delta r s / v_{B I}=0,155$, лінійної залежності рис. 2 , має такий же самий порядок величини, як і міжланцюгова відстань ненаповненого каучуку (див. вище); в будь-якому випадку можна сказати, що ГШ, утворений $з$ моно шарів, щільно упакованих сегментів каучуку, для розрахунків було прийнято $s \approx 300 \mathrm{M}^{2} / \Gamma$ та $v_{B I} \approx 0,74 \mathrm{~cm}^{3} / \Gamma$ [7].

На кривих МКРР для вихідного каучуку не було зафіксовано ніяких гетерогенностей (точкова лінія на рис. 1б). На кривих МКРР для чистого наповню-

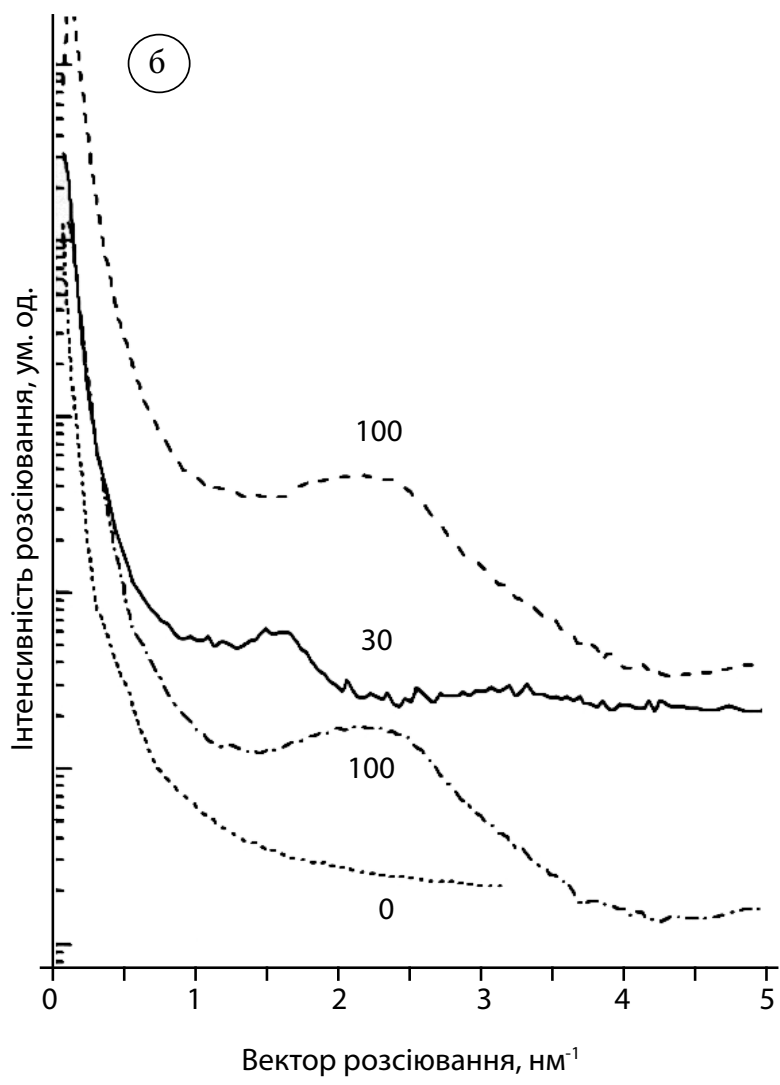

\section{пояснення в тексті}


ження єдиного яскраво вираженого малокутового рефлексу при $q \approx 1,56$ нм$^{-1}$ на кривій МКРР, що представлена для зразка CR/OC2-30 (неперервна лінія на рис. 1б), припускає наявність високого ступеня ексфоліації монтморилоніту в матриці каучуку.

Для ненаповнених матеріалів циклічні деформації розтягування/скорочення, як і очікувалось, були повністю оборотними. Експериментальні значення питомої (в одиниці маси $m$ ) механічної роботи $\mathrm{W} / \mathrm{m}$, питомих теплових ефектів $Q / m$ (рис. 3) були приведені до стандартних рівнянь пружності реальних каучуків [8],

$$
\begin{gathered}
\left(\frac{W}{m}\right)_{P, T}=A \frac{E}{6 \rho}\left(\lambda^{2}+\frac{2}{\lambda}-3\right), \\
\left(\frac{Q}{m}\right)_{P, T}=-\left(\frac{W}{m}\right)_{P, T}\left(1-T \beta-\frac{2 \alpha T}{\lambda^{2}+\lambda-2}\right),
\end{gathered}
$$

де:

$$
\begin{aligned}
& \left(\frac{W}{m}\right)_{P, T}-\text { питома робота деформації еластомеру; } \\
& \left(\frac{Q}{m}\right)_{P, T} \text { - питома теплота деформації еластомеру; }
\end{aligned}
$$$$
A=\frac{\left\langle h_{0}^{2}\right\rangle}{\left\langle h^{2}\right\rangle} \approx 1-\text { фронт-фактор; }
$$

$\left\langle h_{0}^{2}\right\rangle$ та $\left\langle h^{2}\right\rangle$ - середньоквадратичні відстані між кінцями вільного незбуреного ланцюга та ланцюга в сітці відповідно;

$E$ - модуль пружності;

$\rho$ - густина;

$\beta=\frac{\partial \ln \left\langle h_{0}^{2}\right\rangle}{\partial T}-$ температурний коефіцієнт незбурених розмірів ланцюга;

$\alpha$ - коефіцієнт об'ємного розширення недеформованого еластомеру;

$\lambda=1+\varepsilon-$ ступінь деформації зразка;

$\varepsilon-$ відносна деформація зразка.

Значення модуля Юнга $E=1,94$ МПа було отримане 3 рівняння (2); потім з експериментальних даних методом нелінійної регресії з допомогою рівняння (3) було отримано параметри $\beta$ та $\alpha$.

Величини $E=1,94$ МПа, $\beta \approx 1,56 \cdot 10^{-3} \mathrm{~K}^{-1}$ та $\alpha \approx 0,98 \cdot 10^{-3} \mathrm{~K}^{-1}$ отримані шляхом обробки експериментальних даних, представлених на рис. 4, згідно 3 рівняннями (2) та (3) у всьому діапазоні відносних видовжень.

На відміну від вихідного каучуку, для всіх композитів незворотні ефекти, які проявляють себе у відхиленнях між $W / m$ та $Q / m$ в циклах розтягування/

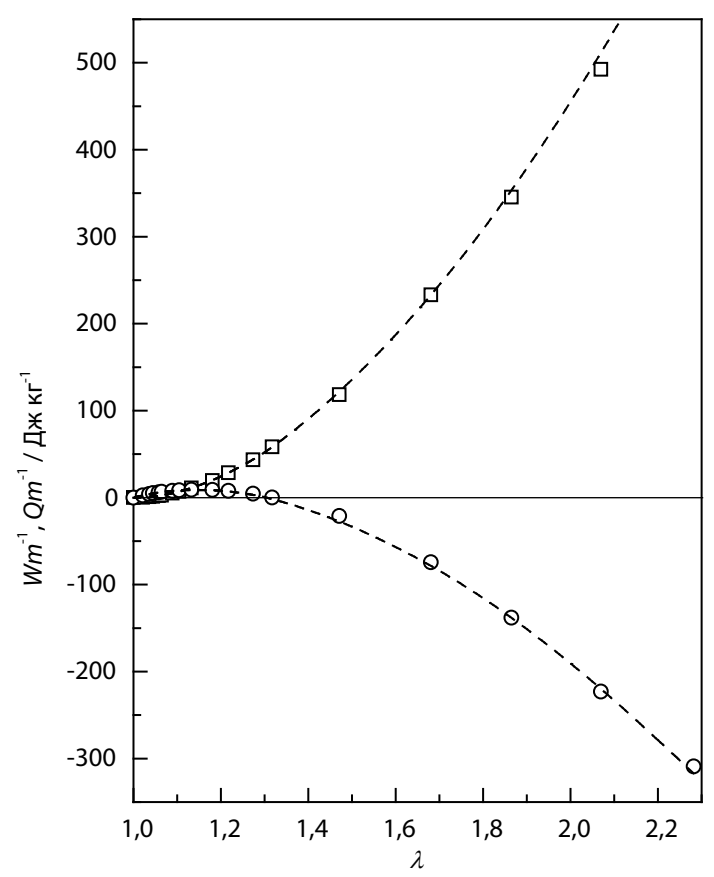

Рис. 3. Залежності питомої механічної роботи (квадрати) та питомої теплоти (окружності) для ненаповненої гуми.

Штрихові лінії - параметри нелінійної регресії, визначеної за допомогою рівнянь (2) та (3)

скорочення, відбуваються вже при низьких деформаціях.

Відносно велика відмінність між модулем Юнга зразка CR/OC2-2.5 з низьким вмістом органоглини (2,5 мас. \%) та вихідним каучуком CR. Та поступове збільшення $E$ ' із збільшенням концентрації наповнювача $w$ (табл. 1 ) говорить про значний ефект підсилення матриці каучуку нескінченним кластером частинок монтморилоніту.

Відповідно до моделі кластер-кластерної агрегації (ККА) [9], критерієм для утворення нескінченного кластера вище точки перколяції $\varphi$ * $\epsilon$ наступне скейлінгове співвідношення модуля пружності

$$
E^{\prime} \sim \varphi^{\alpha}
$$

де $\varphi$ - об'ємна доля наповнювача, $\alpha=\left(3+d_{f, B}\right) /\left(3-d_{f}\right)$, $d_{f}$ та $d_{f, B}-$ фрактальна розмірність ККА-кластера та основної вітки ККА-кластеру. Експериментальна перевірка рівняння (4) для серій нанокомпозитів, які містять ізометричні частинки наповнювача (такі, як сажа або модельні органічні наносфери), при $\varphi>\varphi^{*} \approx 0,2$ приводить до величини $\alpha \approx 3,5$ [9], яка узгоджується 3 типовими фрактальними розмірностями $d_{f, B} \approx 1,3$ та $d_{f} \approx 1,8$.

Як видно з рис. 4 , експериментальні величини $E$, для нанокомпозитів, які досліджуються в даній роботі, також якісно задовольняють рівняння (4). 


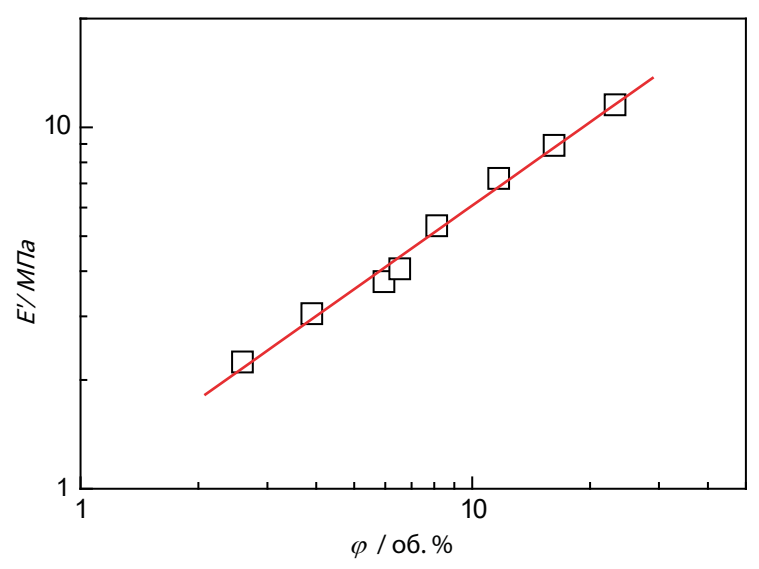

Рис. 4. Залежність $E$ ' від $\varphi$ для нанокомпозитів

Однак, застосування цього рівняння до даних, отриманих в діапазоні об'ємних часток наповнювача $\varphi<0,25$, не очевидно; більше того, величина показника експоненти $\alpha \approx 0,77$ майже в п’ять разів менша.

На нашу думку, причина цих відмінностей криється в різній формі частинок наповнювача. Геометричний поріг перколяції виникнення нескінченного кластера еліпсоїдних частинок, як було показано в роботі [10], зменшується $3 \varphi^{*} \approx 0,28$ (для частинок 3 характеристичним співвідношенням $l / d \approx 1$ ) до $\varphi^{*} \approx 0,04$ (для $l / d \approx 1 / 20$ ). Отже, виникнення нескінченного кластера сильно анізометричних частинок монтморилоніту відбувається при наповненні нижче або рівному $\varphi \approx 0,04$ (рис. 4 ) та видається теоретично можливим.

Як видно з графіка для зразка CR/OC2-30 (рис. 5), а також $з$ подібних даних, отриманих для інших каучукових нанокомпозитів, відхилення між експериментальними величинами, між $W / m$ та $Q / m$ та теоретичними кривими, які розраховані з допомогою рівнянь (2) та (3) в припущенні оборотності (штрихована лінія), монотонно зростають зі збільшенням відносного видовження. Ці відхилення можна віднести до необоротних структурних змін нескінченного кластера частинок наповнювача, які враховуються наступними рівняннями

$$
\begin{gathered}
\left(\frac{W}{m}\right)_{P, T}=A \frac{E}{6 \rho}\left(\lambda_{\mathrm{int}}^{2}+\frac{2}{\lambda_{\mathrm{int}}}-3\right), \\
\left(\frac{Q}{m}\right)_{P, T}=-\left(\frac{W}{m}\right)_{P, T}\left(1-T \beta-\frac{2 \alpha T}{\lambda_{\mathrm{int}}{ }^{2}+\lambda_{\mathrm{int}}-2}+C\right),
\end{gathered}
$$

де $\lambda_{\text {int }}=1+\varepsilon X$ нормалізоване відносне видовження, $X \approx X_{\infty}+\left(X_{0}-X_{\infty}\right) \exp \left(-z \varepsilon_{\text {max }}\right), X_{0}, X_{\infty}$ та $z-$ фітингові параметри, $\varepsilon_{\max }-$ це максимальна деформація при кожному поступовому кроці навантаження, $C$ - це емпірична поправка для теплоти, яка виділяється при зовнішньому терті між частинками наповнювача в процесі деформація/фрагментація нескінченного кластера.

Як видно з рис. 5 (неперервні лінії), експериментальні дані кількісно узгоджуються з рівняннями (5) та (6), фітингові параметри перелічені в табл. 1. Ці дані дають додаткове підтвердження концепції про фактор підсилення, який залежить від деформації та визначає термопружні властивості нанокомпозитів.

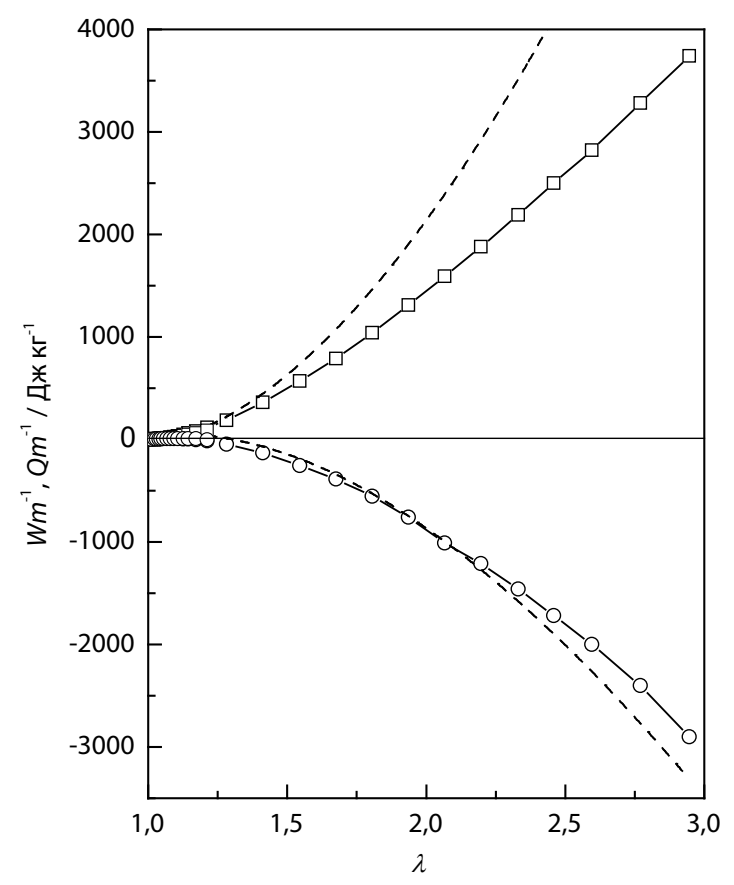

Рис. 5. Залежність, відповідно, питомих механічної роботи (квадрати) та теплоти (окружності) для зразка CR/OC2-30.

Штриховані та неперервні лінії: параметри нелінійної регресії рівняння (5) та (6) відповідно

Приблизно однакові значення величини $z$ передбачають однакову фрактальну розмірність [7] початкового нескінченного кластера частинок органоглини у всіх досліджуваних нанокомпозитах, тоді як тенденція до збільшення початкового $X_{0}$ та кінцевого $X_{\infty}$ фактора підсилення із вмістом наповнювача також $є$ очікуваною. Однак складно пояснити низькі величини корекційної складової $C$. Величини $C$ проявляють тенденцію до зростання тим краще, чим слабкіша взаємодія на міжфазній поверхні каучук/наповнювач (тобто, чим більший масштаб рухів між частинками при поступовому руйнуванні початкового нескінченного кластера наночастинок на менші за розмірами, ізольовані кластери, що визначається різницею між $X_{0}$ та $\left.X_{\infty}\right)$. 
В термінах цього критерію для значень величини $C$ нижче за $0,10-0,35$ можна очікувати, що $\left(X_{0}-X_{\infty}\right) \rightarrow 0$, яке, очевидно, не спостерігається в нашому випадку (табл. 1).

Таким чином, явище механічного гістерезису пояснюється тим, що із збільшенням кратності видовження початкові просторові агрегати частинок наповнювача, які простираються по всьому об'єму зразка, руйнуються на менші фрагменти (ізольовані кластери); однак розмір останніх залишається постійним в наступних циклах розтягування/скорочення до тих пір, поки не перевищене максимальне розтягування. Більш того, було показано, що екзотермічні ефекти зовнішнього тертя між частинками, які проявляються під час поступового руйнування просторової сітки частинок наповнювача, залежать від природи наповнювача та енергії взаємодії на міжфазній поверхні каучук/наповнювач. Фактор підсилення деформації, який залежить від попереднього видовження, є основним параметром, який відповідає за термопружні властивості нанокомпозитів на основі каучукової матриці.

\section{Висновки}

1. Сильні взаємодії на поверхні розділу в нанокомпозитах відповідають за формування граничного шару (ГШ) мономолекулярної товщини з кристалоподібним упакуванням сегментів.

2. Виникнення нескінченного кластера сильно анізометричних частинок, покритих ГШ органоглини при наповненні, нижче або рівне $\varphi \approx 0,04$.

3. Кількісний аналіз термопружних властивостей каучукових нанокомпозитів дає додаткове підтвердження концепції про фактор підсилення, який залежить від деформації, та визначає термопружні властивості нанокомпозитів для всього діапазону відносних видовжень.

\section{References}

1. Kraus, G. (ed.). Reinforcement of Elastomers. Interscience Publ. - New York. - 1965.

2. Fukushima, Y.; Inagaki, S. Synthesis of an intercalated compound of montmorillonite and 6-polyamide.

J. Inclusion Phenom. - 1987. - 5. - P. 473 - 482.

3. Varghese, S., Karger-Kocsis, J., Gatos, K.G. Melt compounded epoxidized natural rubber/layered silicate nanocomposites: structure-properties relationships. Polymer, 44. - 2003. - P. 3977 - 3983.

4. Schön, F. PhD Thesis. Institut für Makromolekulare Chemie, Universität Freiburg. - 2004.

5. Миронц̧ов, Л.И. Термодинамика деформации сегментированных полиуретанов. Дисс. на соиск. науч. степени канд. хим. наук, ИХВС, АН УССР. Киев. -1987.

6. Privalko, V.P., Novikov, V.V. The Science of Heterogeneous Polymers. John Wiley \& Sons, Chichester. - 1995. 7. Klueppel, M., Schramm, J. A generalized tube model of rubber elasticity and stress softening of filler reinforced elastomer systems. Macromol. Theor. Simul. 2000. - 9. - P. 742 - 754.

8. Godovsky, Yu.K. Thermal Physics of Polymers. Springer Verlag. - Munich. - 1991.

9. Heinrich, G., Klueppel, M. Recent advances in the theory of filler networking in elastomers. Adv. Polymer Sci. - 2002. - 160. - P. 1 - 44.

10. Garboczi, E.J., Snyder, K.A., Douglas, J.F., Thorpe, M.F. Geometrical percolation threshold of overlapping ellipsoids. Phys. Rev. E. - 1995. - 52. - P. 819 - 828.

Таблиця 1.

Значення параметрів нанокомпозитів

\begin{tabular}{|l|c|c|c|c|c|}
\hline Зразок & $E$, МПа & $X_{0}$ & $X_{\infty}$ & $\mathrm{z}$ & $\mathrm{C}$ \\
\hline $\mathrm{CR}$ & 1,944 & - & - & - & - \\
\hline $\mathrm{CR} / \mathrm{OC} 2-2,5$ & 2,12 & 22,20181 & 16,96275 & 0,6 & 0,1 \\
\hline $\mathrm{CR} / \mathrm{OC} 2-5$ & 2,242 & 24,032 & 18,856 & 0,6 & 0,21 \\
\hline $\mathrm{CR} / \mathrm{OC} 2-7,5$ & 3,05 & 28,01317 & 22,0731 & 0,6 & 0,28 \\
\hline $\mathrm{CR} / \mathrm{OC} 2-10$ & 3,74 & 28,13432 & 22,9585 & 0,612 & 0,35 \\
\hline $\mathrm{CR} / \mathrm{OC} 2-12,5$ & 4,06 & 33,56527 & 25,82612 & 0,6 & 0,24 \\
\hline $\mathrm{CR} / \mathrm{OC} 2-15$ & 5,34 & 33,88819 & 26,38043 & 0,6 & 0,29 \\
\hline $\mathrm{CR} / \mathrm{OC} 2-20$ & 7,22 & 40,41384 & 29,59809 & 0,598 & 0,26 \\
\hline $\mathrm{CR} / \mathrm{OC} 2-30$ & 8,91 & 43,39886 & 33,01568 & 0,6232 & 0,25 \\
\hline $\mathrm{CR} / \mathrm{OC} 2-40$ & 11,54 & 51,0174 & 39,92702 & 0,614 & 0,16 \\
\hline
\end{tabular}

